\title{
Measurement and analysis of bridge expansion joint noise
}

\author{
Dingtao $\mathrm{Mao}^{1}$, and Yong Ding ${ }^{1, *}$ \\ ${ }^{1}$ Department of Civil Engineering, 315211 Ningbo, China
}

\begin{abstract}
The structure-borne noise while the vehicle passing across the bridge expansion joint is the main source of urban bridge noise. In order to control this noise pollution, 20 bridges including three types of typical expansion joints in Ningbo City were selected, and the noises were measured while vehicle passed across the bridge expansion joints. The measured results are expressed by the Z-weighted sound pressure level, which kept the effect of the low-frequency noise. Then the influence factors of this noise are discussed. The results show that: (1) The sound pressure while vehicle on the bridge expansion joints is much greater than that on the normal road or mid-span of the bridges, which results in significant environmental noise pollution; (2) The wider the gap of the bridge expansion joints, the greater the noise level; (3) The noises produced by the modular expansion joints and comb-plate expansion joints are greater than that from the single-gap expansion joints.
\end{abstract}

\section{Introduction}

With the development of urban modernization, the number of viaduct roads has increased significantly. Ghimire [1] and Sexton [2] pointed out that the noise generated by vehicles passing bridges, especially the bridge expansion joints, has become a kind of environmental pollution. Therefore, it is very important to analyse the noise of bridge expansion joints. There are many work on the noise of the main structure of the bridge, but only a few researches on the noise of the bridge expansion joints. Wakefield [3] measured the sound pressure level of modular bridge expansion joints; Ghimire [4-5] used the boundary element method to simulate the structure noise of bridge expansion joints; Ding [6] found that the traffic load has a great impact on the bridge expansion joint structure, and will produce large noise radiation; Glaeser [7] proposed that the noise of bridge expansion joints is the result of vehicle tire impacting the discontinuous surface profile of expansion joints.

Up to now, the work of using the measured data to analyse the noise of the bridge expansion joint is still lacking. Therefore, more than 20 bridges in Ningbo are selected in this paper, the sound pressure of vehicles passing through the bridge expansion joints are measured, the sound pressure level are calculated, and the influence factors of bridge expansion joint noise are discussed.

\section{Measurement process}

\subsection{Test method}

The sound pressure is measured by using the acoustic sensor of BK4190, the effective frequency range of which is $3.15-20000 \mathrm{~Hz}$. Four-channel acquisition instrument from Beijing BSWA company is used for date collection.

As shown in Figure 1, three test points on the bridge are taken. According to the acoustic test specification [8], each measuring point is 1.2 meters above the bridge deck and 0.2 meters from the inner edge of the pavement. Each test takes about twenty seconds, while the vehicle passes through the bridge. The test date is from June 2016 to October 2016

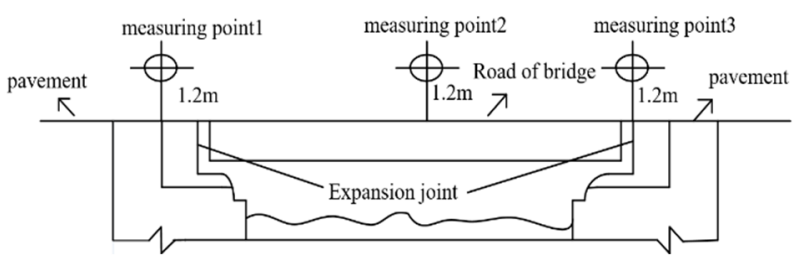

(a) Bridge profile

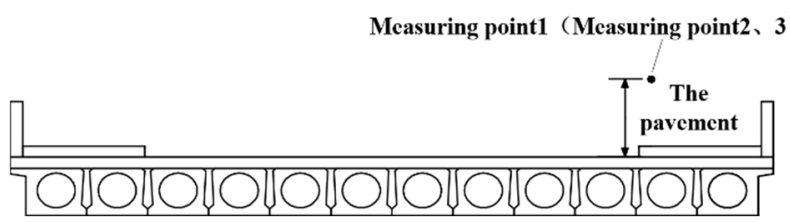

(b) Bridge cross section

Figure 1. Placement of sensors on bridge

\footnotetext{
* Yong Ding: dingyong@nbu.edu.cn
} 


\subsection{Test objects}

It is necessary to measure and analyse the bridge noise by using the Z-weighted sound pressure level, which kept the effect of the low-frequency noise [9]. Therefore, the Zweighted sound pressure is adopted in the measurement of the noise generated by the vehicles passing across the bridge expansion joints. Considering that the test objects should include various types of bridges and expansion joints, after on-site investigation of more than 100 bridges and their expansion joints in Ningbo, 20 of them were selected for field measurement. The selection was based on the fact that there is no large sound interference sources nearby. The bridges are shown in Table 1 and two of them are shown in Figure 2.

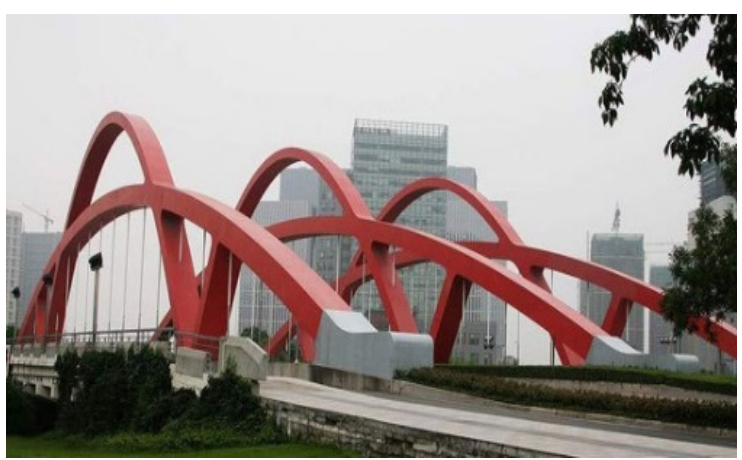

(a) Yuanshi Bridge

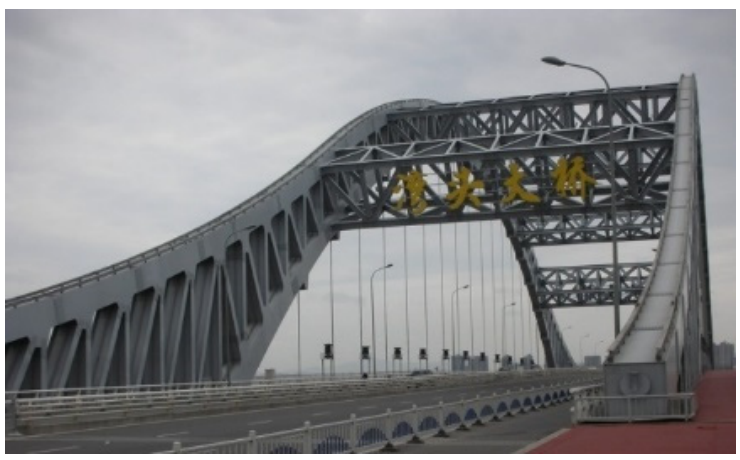

(b) Wantou Bridge

Figure 2. Typical bridges

The types of the bridge expansion joints are shown in Table 2, and several typical expansion joints are shown in Figure 3.

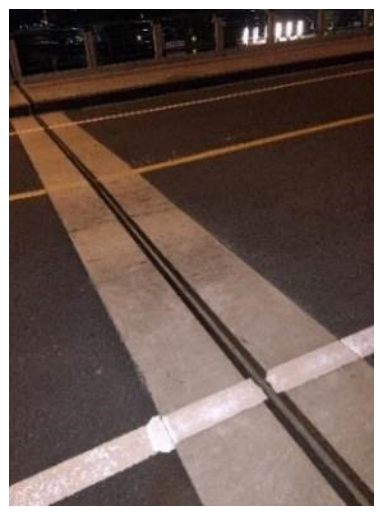

(a) Single-gap expansion joint (Cailian Bridge)

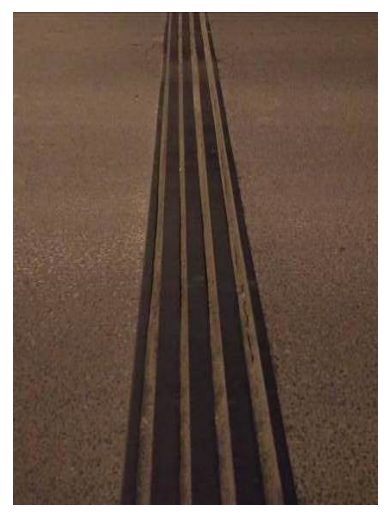

(b) Modular expansion joint (Mingzhou Bridge)

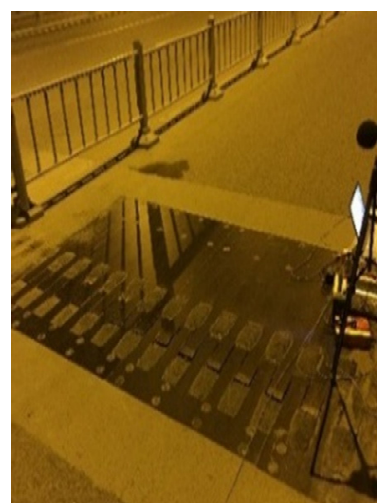

(c) Comb-plate expansion joint (Yongjiang Bridge)

Figure 3. Various types of typical expansion joints

\subsection{Data process}

During the test, it is necessary to reduce the influence of surrounding noises on the bridge expansion joint noise. Therefore, the noise is measured in the mid-night, and the typical sound pressure is shown in Figure 4.

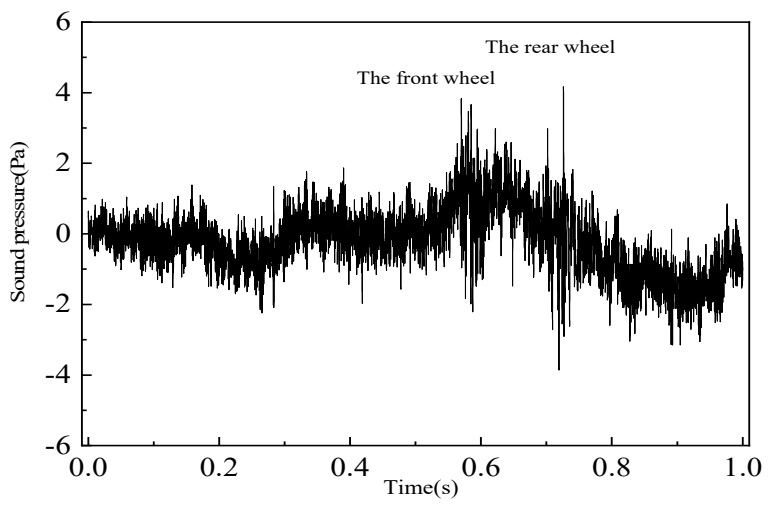

Figure 4. The time-history sound pressure of the vehicle passing across the expansion joint (Cailian Bridge)

When the vehicle passing the normal road or mid-span of the bridge, the main sources of the noise are the vehicle noise and the friction noise between tire and road. When the front and rear wheels of the vehicle are on the bridge expansion joint, it generates structural noise [6-7], and it is observed that the vehicle jumping on the expansion joints, that causes the low-frequency noise because of the vibration of the bridge structures [9-10]. 
Table1. Statistics of bridge types

\begin{tabular}{cccccc}
\hline Bridge type & $\begin{array}{c}\text { Simple beam } \\
\text { bridge }\end{array}$ & $\begin{array}{c}\text { Continuous } \\
\text { beam bridge }\end{array}$ & Arch bridge & $\begin{array}{c}\text { Cable- } \\
\text { stayed } \\
\text { bridge }\end{array}$ & $\begin{array}{c}\text { Suspension } \\
\text { bridge }\end{array}$ \\
\hline Amount & 8 & 6 & 3 & 2 & 1 \\
\hline
\end{tabular}

Table2. Statistics of expansion joints

\begin{tabular}{cccc}
\hline Expansion joint type & $\begin{array}{c}\text { Single-gap expansion } \\
\text { joint }\end{array}$ & Modular expansion joint & $\begin{array}{c}\text { Comb-plate expansion } \\
\text { joint }\end{array}$ \\
\hline Amount & 15 & 2 & 5 \\
\hline
\end{tabular}

In Figure 4, the peak value of the sound pressure occurs when the wheels passing across the expansion joint, and the low-frequency fluctuation of the sound pressure is caused by the influence of wind pressure on the acoustic sensor [11].

According to the measured sound pressure, the sound pressure level is calculated by the following formula

$$
L_{P}=20 \times \frac{\lg P}{\lg P_{0}}
$$

Where $L_{P}$ is the sound pressure level (dB), $P$ is the measured sound pressure, and $P_{0}$ is the standard sound pressure, which is taken as $2 \times 10^{-5} \mathrm{~Pa}$.

\section{Measured results and analysis of influence factors}

\subsection{Bridge expansion joint noise}

From the time-history of expansion joint noise shown in Figure 4, it can be seen that two peaks of the sound pressure appear when the front and rear wheels of the vehicle passing across the bridge expansion joint, respectively. And these two sound pressure are much greater than the others Therefore, the bridge expansion joint noise is an important source of the traffic noise of bridge structure.

In order to verify this conclusion, a series of measurement of sound pressure are performed on the single-gap expansion joints of Yuanshi Bridge and Wantou Bridge (Figure 2) while vehicles passing across.

The measured sound pressure when the vehicle on the mid-span of the bridge are compared with that when the vehicle on the bridge expansion joint.

The measuring point 1 and 3 are beside the bridge expansion joints, and the measuring point 2 are beside the mid-span of the bridge.

The average sound pressure levels are calculated after multiple measurements, and they are shown in Tables 3 and 4 . It indicates thatthe noise of bridge expansion joint is much greater than that of the bridge structure.

The environmental standard [8] suggests that the acceptable sound pressure level for human body is form $60 \mathrm{~dB}$ to $70 \mathrm{~dB}$. However, the sound pressure level of the bridge expansion joints when vehicle passing across reaches $80-100 \mathrm{~dB}$. This phenomenon needs to be paid enough attention.

\subsection{Analysis of influence factors of expansion joint noise}

\subsubsection{Width of the gaps in expansion joint}

It can be seen from Table 3 and Table 4 that the average noise of bridge expansion joints generated by vehicles on the Yuanshi Bridge is greater than that on the Wantou Bridge.

During the test, it was found that the width of the single-gap expansion joints on the Yuanshi Bridge is 2$3 \mathrm{~mm}$ larger than that on the Wantou Bridge, which may be one of the factors causing the differences of the noise of bridge expansion joints.

In order to confirm the conclusion, the cement truck passing the single-gap expansion joint is taken as an example. A series of noise measurements are performed for the bridges on the Huizhan Road and Chuangyuan Road. The maximum sound pressure when the vehicles passing across the bridge expansion joints are obtained, and the relationship between the maximum sound pressure level and the width of the gaps in bridge expansion joints are shown in Figure 5.

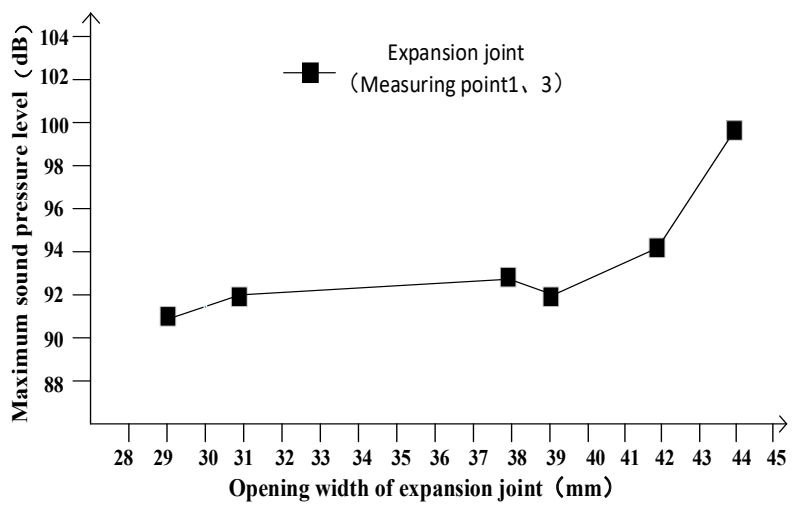

Figure 5. The maximum sound pressure level varies with the width of the gap in bridge expansion joints

Figure 5 shows that as the width of the gap of singlegap expansion joint increases, the noise generally rises. The reason is that the wider the gap of the bridge expansion joints, the more serious of vehicle jumping on the expansion joints, and the greater the low-frequency noise because of the vibration of the bridge structures. 
Table3. Sound pressure level of the expansion joint of Yuanshi bridge

\begin{tabular}{cccc}
\hline Vehicle Type & $\begin{array}{c}\text { Point } 1 \text { beside the } \\
\text { expansion joint }\end{array}$ & $\begin{array}{c}\text { Point } 2 \text { beiside the } \\
\text { mid-span of bridge }\end{array}$ & $\begin{array}{c}\text { Point } 3 \text { beside the } \\
\text { expansion joint }\end{array}$ \\
\hline Cement truck & 88.9 & 59.7 & 86.6 \\
Bus & 83.1 & 56.7 & 82.3 \\
Mini bus & 81.7 & 58.0 & 82.7 \\
\hline
\end{tabular}

Table4. Sound pressure level of the expansion joint of Wantou Bridge

\begin{tabular}{cccc}
\hline Vehicle Type & $\begin{array}{c}\text { Point } 1 \text { beside the } \\
\text { expansion joint }\end{array}$ & $\begin{array}{c}\text { Point 2 beiside the } \\
\text { mid-span of bridge }\end{array}$ & $\begin{array}{c}\text { Point } 3 \text { beside the } \\
\text { expansion joint }\end{array}$ \\
\hline Cement truck & 83.8 & 53.8 & 83.6 \\
Bus & 76.7 & 53.6 & 79.4 \\
Mini bus & 75.2 & 53.3 & 76.0 \\
\hline
\end{tabular}

Table5. Maximum sound pressure level of different types of bridge expansion joints

\begin{tabular}{ccc}
\hline Number & Type of the expansion joint & Maximum sound pressure level \\
\hline 1 & Single-gap expansion joint & 91 \\
2 & Modular expansion joint & 93 \\
3 & Comb-plate expansion joint & 93 \\
\hline
\end{tabular}

\subsubsection{Type of expansion joint}

During the test, the noise of three different types of bridge expansion joints (single-gap expansion joint, modular expansion joint and comb-plate expansion joint) were measured. In order to compare the differences in noise among three different types of expansion joints, the sound pressure level are measured when the cement trucks passing across the expansion joints on Mingzhou bridge, and the results are shown in table 5 .

As shown in Table 5, there is little difference between the noise generated by the modular expansion joint and the comb-plate expansion joint, and both of them are 2-3 $\mathrm{dB}$ higher than the noise generated by the single-gap expansion joint. The reason is that the modular expansion joint and the comb-plate expansion joint have more complex structures and wider gaps, which produce greater sound pressure [4-5, 12-13].

\section{Conclusion}

Based on the measured sound pressure of the expansion joints of 20 bridges in Ningbo, the sound pressure level is calculated, and the influence factors of bridge expansion joint noise are discussed. The conclusions are as follows.

(1) The sound pressure while vehicle on the bridge expansion joints is much greater than that on the normal road or mid-span of the bridges, which results in obvious noise pollution, that needs to be paid enough attention;

(2) The wider the gap of the bridge expansion joints, the more obvious the vehicles jumping on the expansion joints, and the greater the low-frequency noise because of the vibration of the bridge structures. Therefore, the noise can be controlled by reducing the width of the gap in expansion joints;

(3) The noise generated by the modular expansion joints and the comb-plate expansion joints are greater than that generated by the single-gap expansion joints.

\section{Acknowledgements}

This work has been supported by the Natural Science Foundation of Zhejiang Province (LY19E080009), the Comprehensive Insurance for Country Road in Haishu District of Ningbo City, and Ningbo Transportation Science and Technology Project (202104).

\section{References}

1. Ghimire J P, Matsumoto Y, Yamaguchi H, Noise Control Eng J, 56 (2008)

2. Sexton T, INCEJ and ASJ, 734-739 (2011)

3. Wakefield C W, Marriner, Duane E, Can Acoust, 39 (2011)

4. Ghimire J P, Matsumoto Y, Yamaguchi H, J. Sound Vib., 328 (2009)

5. Ghimire J P, Matsumoto Y, Yamaguchi H, Noise Control Eng J, 56:442-450(9) (2008)

6. Ding Y, Zhang W, Francis T.K. Au, Eng. Struct., 127 (2016)

7. Glaeser K P, Schwalbe G, Zöller M, INCEJ and ASJ 753-762 (2011)

8. AQSIQ, Environmental quality standard for noise(GB 3096-2008) (2008)

9. Zhang W, Jin T, Ding Y, UEUE, 42-46 (2015)

10. Xie X, Wu D Y, Wang J F, JZU, 43(2009)

11. Ravshanovich K A, Yamaguchi H, Matsumoto Y, Eng. Struct., 29 (2007)

12. Mao W S, JURBFC, 7 (2013)

13. Wang C K, JCT, 43 (2016) 